\title{
Modeling and Simulation of Iron Ore Sintering Process with Consideration of Granule Growth
}

\author{
Bin ZHANG, Jiemin ZHOU, Mao LI* and Yuan LI \\ School of Energy Science and Engineering, Central South University, No. 932, Lushan South Road, Changsha City, Hunan \\ Province, 410083 P. R. China.
}

(Received on June 27, 2017; accepted on September 26, 2017)

\begin{abstract}
Granule growth is an important process for iron ore sintering process. Variation of granule size has a great influence on the quality of sinter and productivity of the process. In this study, a model of granule growth was proposed based on two dimensional homogeneous sphere packing theory. The sintering process was simulated by an unsteady two-dimensional mathematical model which incorporates most of the significant physical phenomena and chemical reactions. Numerical simulation was carried out by FLUENT software and $\mathrm{C}$ language programming via developing custom code. Sinter pot tests were performed and experimental data reasonably agreed with the simulation. Results showed that granules diameter changed from $3 \mathrm{~mm}$ to $31.9 \mathrm{~mm}$, which increased nearly ten times, while sintering time and yield can be estimated. Simulations were conducted under different initial iron ore size to investigate its effect on sintering. Results showed that larger agglomeration were formed and thickness of molten zone was decreased under larger initial iron ore size, which shortened sintering time and increased productivity.
\end{abstract}

KEY WORDS: sintering; modeling; numerical simulation; agglomeration; granule growth.

\section{Introduction}

The main purpose of iron ore sintering is to produce iron-bearing agglomeration as a burden for blast furnace. The feed material melts partially and agglomerates at a high temperature in the sintering bed, then the semi-molten material solidifies and crystallizes into various mineral phases in subsequent cooling period. ${ }^{1)}$ Figure 1 shows a conceptual version of the iron ore sintering process in sinter pot.

In recent decades, numerical simulation, as an effective theoretical method complementary to laboratory investigation, is being increasingly applied to analyze iron ore sintering. Various mathematical models of iron ore sintering have been developed. ${ }^{2-5}$ It has been proved useful in analyzing the sintering performance ${ }^{6,7)}$ and developing new technologies. $^{8-10)}$ Besides, some researchers investigated the agglomeration phenomenon of granules and structural changes. ${ }^{11,12)}$ However, the process of granule growth was omitted in some previous mathematical models, which implies that agglomeration of particles was not considered. Variation of granule size affects permeability directly, and eventually affects temperature distribution and sintering performance. Therefore, there is still great potential to improve the model of the iron ore sintering.

In this study, an improved mathematical model of iron ore sintering process was developed which considered granule growth and incorporated most of physical phenomena and

* Corresponding author: E-mail: limao89@163.com

DOI: http://dx.doi.org/10.2355/isijinternational.ISIJINT-2017-342

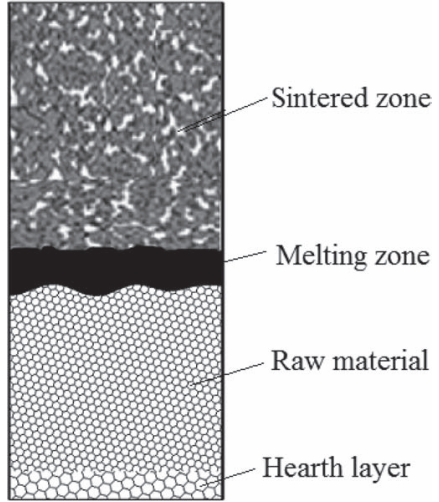

Fig. 1. Schematic diagram of the iron ore sintering process.

chemical reactions. The results were compared with sinter pot tests. Simulations were conducted under different initial iron ore sizes in order to investigate its effect on sinter yield and productivity.

\section{Mathematical Model}

Some reasonable assumptions and simplifications were adopted before modeling the iron ore sintering process. First, the sintering bed was assumed as a particle packed bed and was treated by means of the porous medium hypothesis; the gas phase was regarded as continuum. Second, granules in the raw mixture were assumed to be spherical with specific equivalent diameter and distributed evenly; each particle had a representative temperature owing to its tiny size 
and high conductivity, which means there was no temperature gradient inside each particle. Third, the solid phase was constituted by the components of iron ore, coke, limestone, hematite, magnetite and water; the gas phase was assumed to be a mixture of water vapor, oxygen, carbon dioxide, carbon monoxide, nitrogen and obeyed the ideal gas law. Fourth, shrinkage of the sintering bed was neglected.

\subsection{Conservation Equations}

Changes in mass, energy, momentum and species for both gas and solid phases are caused by gas-solid reactions, moisture transferring, melting and et al. Conservation equations for each phase are shown in Table 1.

The index $i$ represents moisture transferring, coke combustion, limestone decomposition, magnetite oxidation, hematite reduction, carbon monoxide oxidation, and reaction of carbon monoxide with water vapor from 1 to 7 respectively.

In the sintering process, water transfers from solid to gas when evaporating and transfers inversely when condensing while the quantity of exchanged mass between two phases are the same. Reactions 2 to 5 are gas-solid reactions which can lead to the change of both solid and gas masses. Reactions 6 and 7 just occur between different gas components, which only have impact on the mass of gas phase. Changes in solid mass are considerable since the water in the solid phase accounts for $6-12 \%$ of the mixture mass. ${ }^{13)}$ Thus mass conservation equation of the solid phase should not be omitted.

The first and second terms on the left side of the energy conservation equations represent the unsteady term and the convection term. The first term on the right side of the equations is the diffusion term. Other terms are convection heat, evaporation or condensation heat, melting or solidifying heat, and volumetric reaction heat.

Due to numerous and complicated chemical reactions involved in the iron ore sintering process, only the main physical phenomena and chemical reactions were taken into consideration. Heat transfers from solid to gas phase when evaporating and vice versa when condensing. Evaporation and condensation heat are equal and opposite in the energy equations. Melting and solidification just occur in the solid phase, so the melting and solidification heat only have impacts on the solid phase. Chemical reactions were classified into gas-phase reactions and solid-phase reactions, which implies that the heat released or absorbed by gasphase reactions only affect gas temperature, and so does the solid-phase to solid temperature. ${ }^{14)}$

\subsection{Sub-models}

\subsubsection{Granule Growth}

Some correlations of granule growth were adopted in previous simulation of the iron ore sintering process as listed in Table 2.

As can be observed, calculated sinter diameter was 10 mm with initial granule diameter of $3 \mathrm{~mm},{ }^{15}$ ) while the calculated sinter diameter were not given in other two literatures. According to experimental data, ${ }^{16)}$ average size of the sinter varies between $30-42 \mathrm{~mm}$ with the initial diameter of granules of $3.2 \mathrm{~mm}$.

Particles of raw mixture including iron ore, coke fine, limestone and et al. are pelletized into granules. Typically the mean diameter of iron ore particle is controlled at 3-5 $\mathrm{mm}$. Coarser particle inclines to become the nuclei with the size of $+1 \mathrm{~mm}$, while the adhering particles including coke, limestone and et al. are $-0.5 \mathrm{~mm}$ in size. ${ }^{17)}$ Sketch of a granule is shown in Fig. 2.

Finer particles with radius of $r$ are adhering on a nuclei particle which has a radius of $R$. Number of adhering particles $n$ could be calculated according to structural characteristic of the granule, which is expressed as follows:

Table 2. Granule growth correlations in previous studies.

\begin{tabular}{cccc}
\hline Researcher & Correlation & $\begin{array}{c}\text { Initial granule } \\
\text { diameter }\end{array}$ & $\begin{array}{c}\text { Calculated } \\
\text { sinter } \\
\text { diameter }\end{array}$ \\
\hline W. Yang & $d_{p}=\left[(1-F) d_{u}^{3}+F d_{r}^{3}\right]^{1 / 3}$ & $3 \mathrm{~mm}$ & - \\
V. Strezov & & & \\
& $d_{p}=d_{p_{0}}+K \frac{T_{s}-1473}{400}$ & $4 \mathrm{~mm}$ & - \\
B. Liu' & & & \\
& $d_{p}=d_{p_{0}}+\frac{\left(T_{s}-T_{l}\right)\left(d_{p_{l}}-d_{p_{0}}\right)}{T_{\max }-T}$ & $3 \mathrm{~mm}$ & $10 \mathrm{~mm}$
\end{tabular}

Table 1. Conservation equations.

\begin{tabular}{|c|c|c|c|}
\hline \multirow{2}{*}{$\begin{array}{l}\text { Solid } \\
\text { phase }\end{array}$} & Mass & $\frac{\partial\left(\varepsilon \rho_{g}\right)}{\partial \tau}+\nabla \cdot\left(\rho_{g} v\right)=\sum_{i=1}^{7} R_{i}$ & (1) \\
\hline & Energy & $(1-\varepsilon) \cdot c_{s} \rho_{b} \frac{\partial T_{s}}{\partial \tau}=\nabla \cdot\left(\lambda_{s, e} \nabla T_{s}\right)+h_{v}\left(T_{g}-T_{s}\right)-R_{1} \Delta H_{1}+q_{m}+\sum_{i=2}^{5} R_{i} \Delta H_{i}$ & (2) \\
\hline \multirow{4}{*}{$\begin{array}{l}\text { Gas } \\
\text { phase }\end{array}$} & Mass & $\frac{\partial \rho_{b}}{\partial \tau}=-\sum_{i=1}^{5} R_{i}$ & (3) \\
\hline & Energy & $\varepsilon \cdot c_{p, g} \rho_{g} \frac{\partial T_{g}}{\partial \tau}+\nabla\left(c_{p, g} \rho_{g} T_{g} v \cdot \varepsilon\right)=\nabla \cdot\left(\lambda_{g} \nabla T_{g}\right)+h_{v}\left(T_{s}-T_{g}\right)+R_{1} \Delta H_{1}+\sum_{i=6}^{7} \Delta R_{i} H_{i}$ & (4) \\
\hline & Momentum & $\frac{\partial}{\partial \tau}\left(\rho_{g} v_{i}\right)+\nabla \cdot\left(\rho_{g} v_{i} v_{j}\right)=-\nabla \cdot P+\rho_{g} g_{i}+\rho_{g} f_{i}$ & (5) \\
\hline & Species & $\frac{\partial\left(\varepsilon \rho_{g} Y_{i}\right)}{\partial \tau}+\nabla \cdot\left(\rho_{g} v \cdot Y_{i}\right)=\sum_{i=1}^{7} R_{i}$ & (6) \\
\hline
\end{tabular}




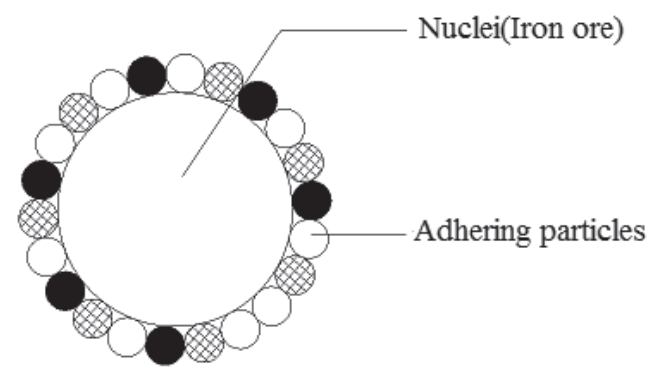

(a) Sketch of a granule.

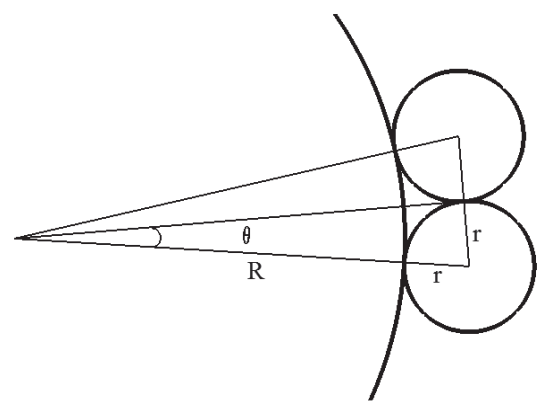

(b) Partially enlarged view of a granule.

Fig. 2. Structure of an initial granule.

$$
n=\frac{\pi}{\arcsin \frac{r}{R+r}}
$$

With increasing of temperature, outside finer particles start to react with the air. Chemical reaction of coke combustion supplies the main heat to the sinter mix and raise the temperature of granule. Iron ore particle starts to soften and liquid drops form at the surface of iron ore particle when the temperature exceeds the melting point. With increasing of melt quantity, the partial melted granule bonds with the neighboring granules and a new sinter agglomeration is formed with a equivalent diameter of $D$. Schematic representation of agglomerating process is shown in Fig. 3.

According to two dimensional homogeneous sphere packing theory, ${ }^{18)}$ the mean solid deposition ratio of packing is 0.63 . Equivalent diameter of the agglomeration can be calculated as follows:

$$
\begin{aligned}
& \frac{\pi D^{2}}{4}=7\left(n \frac{\pi r^{2}}{4}+\frac{\pi R^{2}}{4}\right) / 0.63 \\
& D=\sqrt{\frac{7\left(n r^{2}+R^{2}\right)}{0.63}}
\end{aligned}
$$

Based on the assumption, the agglomeration can be regarded as bonding of several granules. The agglomeration diameter could be increased further with more partial melted granules around when melting condition achieves.

\subsubsection{Other Sub-models}

Heat convection is dominant for heat transfer between gas and solid phase. Volumetric convective heat transfer coefficient $h_{v}$ is determined by: ${ }^{19)}$

$$
h_{v}=6 h(1-\varepsilon) / d_{p}
$$

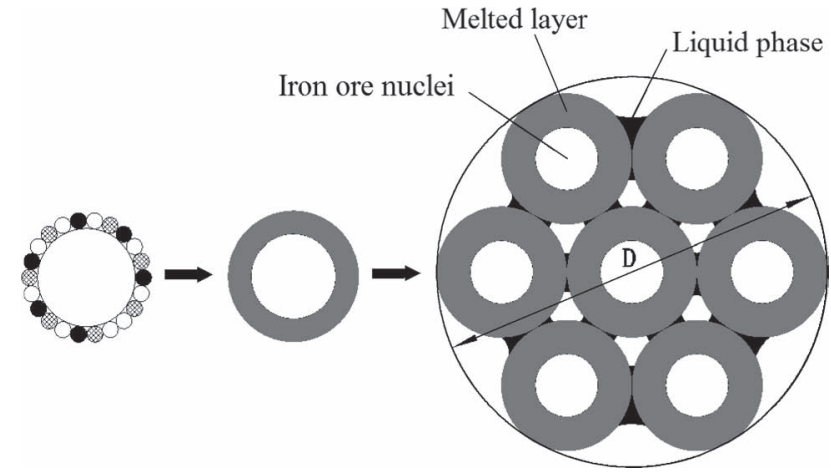

Fig. 3. Schematic representation of agglomerating process.

Convective coefficient $h$ can be derived by the RanzMarshall equation, and the $N u$ number was suggested by Kunii. ${ }^{20)}$

$$
N u=\frac{h d_{p}}{\lambda}=2+0.6 \operatorname{Pr}^{0.333} \operatorname{Re}^{0.5}
$$

In addition, conduction and radiation were considered and effective solid thermal conductivity $\lambda_{s, e}$ was given by. ${ }^{21)}$

$$
\lambda_{s, e}=(1-\varepsilon) \lambda_{s}+4 \sigma \omega \cdot d_{p} \cdot T_{s}^{3}
$$

Patisson's model was used for the prediction of evaporation and condensation which was characterized by two stages, that is a constant rate followed by a decreasing drying rate. ${ }^{22)}$

Melting starts above the melting temperature and solidification begins when the temperature drops below the melting point. The melting or solidification heat is:

$$
q_{m}=-\frac{\partial}{\partial \tau}\left(f_{m} \cdot \Delta H_{m} \cdot \rho_{b}\right)
$$

Volume fraction of the melt is given by: ${ }^{23)}$

$$
f_{m}=\left(T_{s}-T_{m}\right) /\left(T_{\max }-T_{m}\right)
$$

Melting temperature $T_{m}$ changes with the composition of the raw mixture: ${ }^{24)}$

$$
T_{m}=1380+21.22 f_{\mathrm{Al}_{2} \mathrm{O}_{3}}+3.35 f_{\mathrm{SiO}_{2}}-1.8 f_{f l u x} \ldots . .
$$

Where $f_{A 12 O 3}, f_{S i O 2}, f_{f l u x}$ are mass fractions of alumina, silica and flux in charge respectively.

Chemical reactions in the solid phase include coke combustion, limestone decomposition, hematite reduction and magnetite oxidation. Chemical reactions in gas phase include the reactions of carbon monoxide with oxygen and carbon monoxide with water vapor. Reactions adopted in this work are listed in Table 3.

\subsection{Physical Parameters and Porosity}

Changes of physical parameters including specific heat, thermal conductivity and viscosity of solid and gas were considered in this work. Empirical formulas of physical parameters adopted in the simulation are listed in Table 4.

Change of porosity with granule diameter in the sintering bed was considered. The empirical formula presented by Castro was adopted: ${ }^{26)}$

$$
\varepsilon=0.403 \cdot\left(100 d_{p}\right)^{0.14}
$$


Table 3. Reactions used in simulation.

\begin{tabular}{cc}
\hline Reactions & Reference \\
\hline Reactions in the solid phase \\
\hline$(1+\varphi) \mathrm{C}+\left(1+\frac{\varphi}{2}\right) \mathrm{O}_{2} \rightarrow \varphi \mathrm{CO}+\mathrm{CO}_{2}$ & $25)$ \\
$\mathrm{CaCO}_{3} \rightarrow \mathrm{CaO}+\mathrm{CO}_{2}$ & $3)$ \\
$\mathrm{Fe}_{2} \mathrm{O}_{3}+\mathrm{CO} \rightarrow \mathrm{Fe}_{3} \mathrm{O}_{4}+\mathrm{CO}_{2}$ & $16)$ \\
$\mathrm{Fe}_{3} \mathrm{O}_{4}+\mathrm{O}_{2} \rightarrow \mathrm{Fe}_{2} \mathrm{O}_{3}$ & $6)$ \\
\hline $\mathrm{Reactions}$ in the gas phase & \\
\hline $\mathrm{CO}+\mathrm{O}_{2} \rightarrow \mathrm{CO}_{2}$ & $6)$ \\
$\mathrm{CO}+\mathrm{H}_{2} \mathrm{O} \rightarrow \mathrm{CO}_{2}+\mathrm{H}_{2}$ & $16)$ \\
\hline
\end{tabular}

Table 4. Empirical formulas of physical parameters used in simulation.

\begin{tabular}{lcc}
\hline Parameters & Gas phase & Solid phase \\
\hline Specific heat & $910+0.3033 \cdot T_{g}-6.7 \times 10^{-5} T_{g}^{2}$ & $672.3+0.386 T_{s}-\frac{1.076 \times 10^{7}}{T_{s}^{2}}$ \\
$\begin{array}{c}\text { Heat } \\
\text { conductivity }\end{array}$ & $0.15 \cdot \exp \left(-\frac{570}{T_{g}}\right)$ & $0.08 \cdot T_{s}^{0.6}$ \\
Viscosity & $1.72 \times 10^{-5}\left(\frac{T_{\mathrm{g}}}{273}\right)^{1.5} \times\left(\frac{389}{T_{g}+116}\right)$ & \\
\end{tabular}

\subsection{Numerical Solution}

\subsubsection{Initial Conditions}

Initial conditions and parameters used in the simulation are listed in Table $\mathbf{5}$

\subsubsection{Boundary Conditions}

The iron ore sintering process was simulated and computational domain was the same as the configuration of a sinter pot as shown in Fig. 4. The domain was meshed and 18250 rectangular grids were generated with the size of $2.5 \mathrm{~mm} \times$ $2.5 \mathrm{~mm}$. Entrance of the sinter pot was defined as a velocity inlet. The magnitude of velocity was obtained from the experimental gas-flow rate. The bottom of the sinter pot was set to be pressure outlet which was $-6.3 \mathrm{kPa}$ during the ignition stage and maintained at $-12 \mathrm{kPa}$ in the following sintering period. Side walls of the sinter pot were adiabatic.

\subsubsection{Numerical Solution}

Conservation equations of mass, energy, momentum, and species were solved by FLUENT software with C language programming via developing custom code. Changes of mass, energy, flow resistance and species were defined as the source terms in conservation equations. Variables like temperatures $T_{g}, T_{s}$, concentrations like $c_{\mathrm{O} 2}, c_{\mathrm{CO} 2}, c_{\mathrm{H} 2 \mathrm{O}}$ and et al. were defined as scalars. Second-order implicit scheme was used to discretize the transport equations. SIMPLE algorithm was used to couple the velocity and pressure. Residuals of conservation equations were on the order of $10^{-6}$ and the time step was 0.5 second. Relaxation factor of continuum equations and momentum equations were 0.8 and 0.5 respectively.
Table 5. Parameters of simulation.

\begin{tabular}{cc}
\hline Parameters & Value \\
\hline Critical moisture content/\% $\%$ & 5 \\
Time of ignition/s & 90 \\
Temperature of ignition/K & 1423 \\
Time of heat preservation/s & 120 \\
Temperature of heat preservation $/ \mathrm{K}$ & 900 \\
Average diameter of granules/m & 0.003 \\
Bulk density $/ \mathrm{kg} \cdot \mathrm{m}{ }^{-3}$ & 1730 \\
Initial porosity of bed/ & 0.4 \\
Thickness of hearth layer/m & 0.04 \\
Mixed ore $/ \%$ & 64.43 \\
Returned fine/\% & 18.32 \\
Mass fraction of limestone/\% & 7 \\
Mass fraction of coke/\% & 4.2 \\
Actual moisture/\% & 6.05 \\
\hline
\end{tabular}

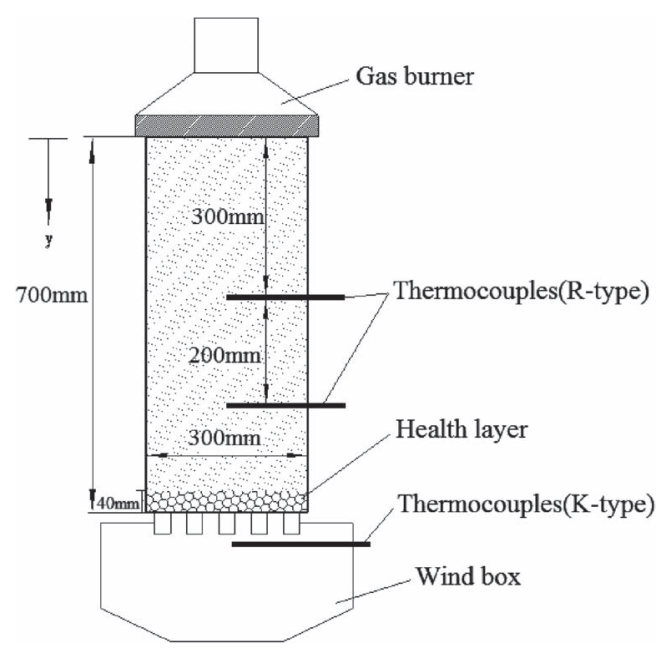

Fig. 4. Schematic diagram of sinter pot test.

\section{Sinter Pot Test and Validation}

\subsection{Sinter Pot Test}

A sinter pot test was conducted with the operating parameters same as the simulation as listed in Table 5. Schematic diagram of sinter pot test was shown in Fig. 4. The sinter pot is $700 \mathrm{~mm}$ high with the diameter of $300 \mathrm{~mm}$. Two R-type thermocouples were inserted in the bed at heights of $\mathrm{y}=300 \mathrm{~mm}$ and $\mathrm{y}=500 \mathrm{~mm}$ and one K-type thermocouple was inserted in wind box.

\subsection{Comparison and Validation}

Owning to shrinkage and slumping of the sinter bed, tips of the fixed thermocouples could not contact the solid tightly and would be exposed to the pores easily. ${ }^{27)}$ Consequently, the temperature measured by thermocouple is an integrated temperature between the solid and gas. Using outlet gas temperature to validate the model is a better option for the reason that only the gas phase temperature is measured by the thermocouple in wind box. Figure 5 shows measured and calculated temperature profiles of the waste gas. 


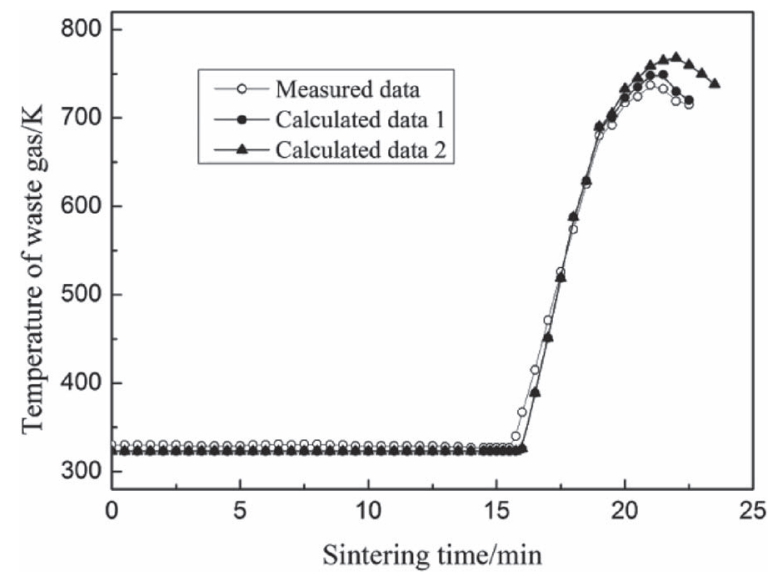

Fig. 5. Measured and calculated data of gas temperature at outlet.

Profile of Calculated data 1 is the simulated outlet gas temperature, which is close to the measured data. Relative error between calculated waste gas temperature and the measured was less than $5 \%$. The reason for the deviation is the wall effect which makes hot air flow along the sidewall directly at the beginning of sintering and results in a rise of waste gas temperature. Besides, shrinkage of bed makes cold air flow into the bottom of bed and leads to a decrease in the measured temperature. Therefore, the calculated data are a little lower than the measured at the beginning of the sintering process, and the peak value is a little higher than the measured.

Simulation was carried out without considering granules growth. Simulated outlet gas temperature profile is Calculated data 2 as shown in Fig. 5. It can be observed that the error between measured and calculated data increased especially at the end of sintering. Therefore, the model could be more accurate with consideration of granule growth.

In addition, the burn through point can be observed from the waste gas profile when gas temperature reaches the highest value. Thus, the sintering time could be predicted. Besides, calculated average diameter of the agglomeration is $31.9 \mathrm{~mm}$ with initial diameter of granules is $3 \mathrm{~mm}$, which means that the diameter of granules increases nearly ten times. Meanwhile, the fired sinter plug was removed from the pot, cooled and weighed. Then the plug was dropped from $2 \mathrm{~m}$-height three times. The over $40 \mathrm{~mm}$ sinter was crushed to less than $40 \mathrm{~mm}$ using a jaw crusher. The shattered sinter was screened at 40,25, 16, 10 and $5 \mathrm{~mm}$, and the weight of each size fraction was obtained. ${ }^{28)}$ According to the measured weight fractions of different size ranges, the calculated mean diameter of the sinter was $29.8 \mathrm{~mm}$. The calculation was in line with the experimental data, which proved that model of granule growth is reliable.

\section{Analysis and Discussion}

\subsection{Solid Temperature Profile}

Except for the sintering time and average diameter of the agglomeration, some other parameters can be obtained from the simulation.

Solid temperature is the main driving force of chemical reactions and physical changes. By using numerical simulation, can the temperatures of the solid and gas be distin-

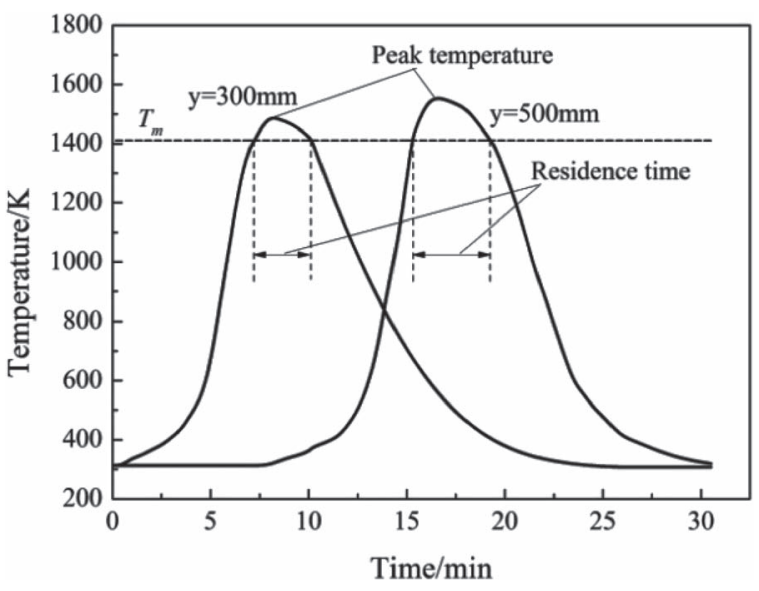

Fig. 6. Calculated solid temperature profile.

guished. Therefore, it makes sense to analyze the characteristics of temperature profiles quantitatively. Figure $\mathbf{6}$ shows calculated solid temperature profiles at the height of $y=300$ $\mathrm{mm}$ and $\mathrm{y}=500 \mathrm{~mm}$. Some important characteristics can be derived from this figure. Firstly, peak temperatures can be read from solid temperature curves. Secondly, residence time could be derived which is defined as the time interval when solid temperature is higher than the melting temperature. The melting temperature is the horizontal dotted line at $T_{m}=1411 \mathrm{~K}$ which is decided by mineral components of the raw mixture and calculated according to Eq. (15).

The peak temperatures at the height of $y=300 \mathrm{~mm}$ and $\mathrm{y}=500 \mathrm{~mm}$ are $1491 \mathrm{~K}$ and $1562 \mathrm{~K}$, while residence times are $2.98 \mathrm{~min}$ and $4.66 \mathrm{~min}$. The peak temperature becomes higher and the residence time prolongs with the increase of height, which means that the charge in the lower bed has higher temperature and longer time to melt and agglomerate. Higher temperature will lead to increasing melt fraction while longer residence time will lead to larger diameter of agglomeration especially at the lower sinter bed.

\subsection{Molten Zone and Melt Fraction}

Figure 7 shows contour of solid phase temperature at 6th minute. It can be observed that the molten zone which is the area with temperature above melting point $T_{m}$ mainly located at the upper bed. In order to measure the thickness of molten zone, the molten area was extracted from the solid temperature contour and showed in Fig. 8. The colored bands in Fig. 8 represent the temperature range over melting point. Thickness of the molten zone increases with the sintering progressing downwards due to higher temperature and longer residence time. Thicker molten zone may cause lower permeability in the sintering bed. Therefore greater thickness of molten zone will prolong sintering time and lead to reduction of productivity.

Melt fraction reflects the quantity of molten liquid phase, which is decided by temperature level. According to Eq. (14), profile of calculated melt fraction $f_{m}$ in the sintering bed can be calculated as shown in Fig. 9 .

As can be observed, melt fraction increases gradually with increasing of the height and the maximum value of melt fraction is located at the bottom of the bed. The melting curve declines at the height of $\mathrm{y}=80 \mathrm{~mm}$, which was caused by entering of cold air after ignition period. 


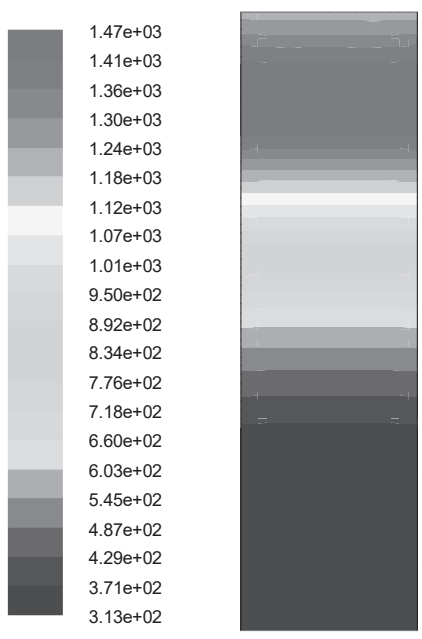

Fig. 7. Contour of solid phase temperature at 6th minute.

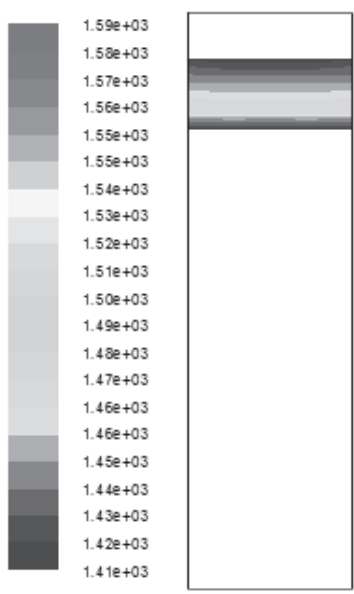

$6 \mathrm{~min}$

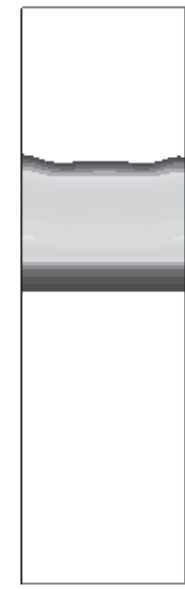

$12 \mathrm{~min}$

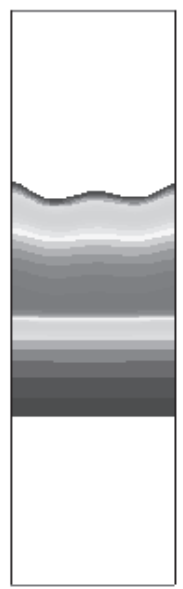

$18 \mathrm{~min}$
Fig. 8. Contours of molten zone at different time.

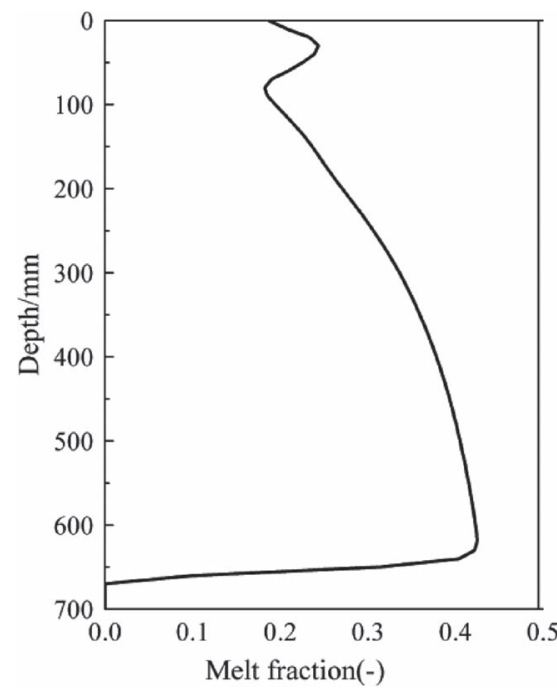

Fig. 9. Melt fraction profile in the sinter pot.

\subsection{Predict of Sinter Yield}

The sinter mix melts partially and forms the product sinter, quality of sinter is mainly dependent on melting degree. It is known that very low melting will result in under-melted sinter and higher return fine percentage, while

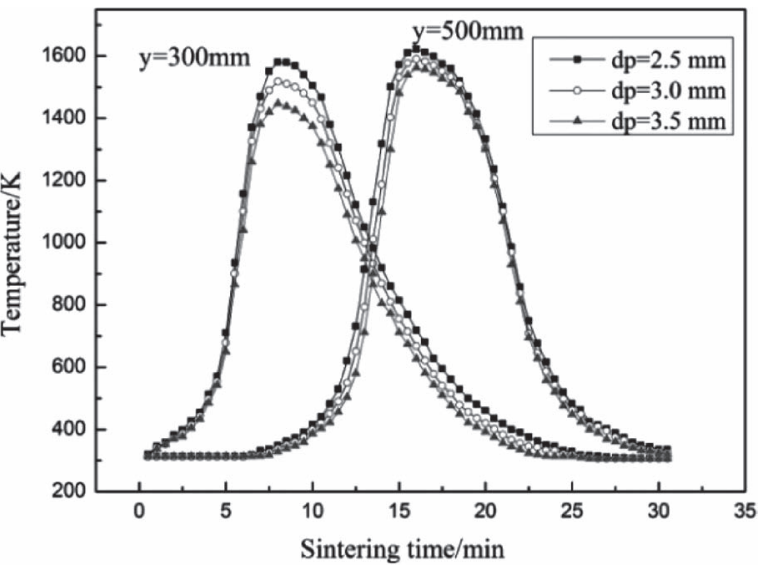

Fig. 10. Solid temperatures vary with sintering time.

excessive melting will result in declining of reducibility. Consequently, sinter quality is determined by the melt fraction to a large extent.

Some researchers proposed that the sinter quality is optimum when melt fraction is $0.3 .^{24)}$ In this study, the sinter mix was assumed to be under-melted when melt fraction was lower than 0.2 , while sinter mix melted excessively when melt fraction exceeded 0.4. When melt fraction was between the range of $0.2-0.4$, the product sinter was considered as qualified.

Based on the assumption, ratio of qualified sinter in the sintering bed indicates the yield of the sintering process. Calculated sinter yield was $63.51 \%$ according to the simulation, while the measured yield of the sinter pot test was $61.96 \%$. The calculated yield was in line with the measured, which verified that the assumption was reasonable.

\subsection{Discussion}

The iron ore has the maximum proportion in the sinter mix. Iron ore size is one of the most important parameters which mainly determines the size of product sinter and affect sinter quality directly. In order to investigate the effect of iron ore size on sintering process, simulations with initial size of $2.5 \mathrm{~mm}, 3 \mathrm{~mm}$ and $3.5 \mathrm{~mm}$ were conducted while keeping other parameters unchanged.

Figure 10 shows solid temperature profiles for different iron ore diameters. Due to coarser iron ore particle has smaller specific surface per volume, less heat will be absorbed per unit time. Therefore, solid temperature decreases with increasing of iron ore particle.

Figure 11 shows variation of melt fraction profiles under different iron ore particle diameters. It can be seen that the melt fraction reduces with increasing of iron ore particle diameter. The difference of melt fraction at the upper bed is greater which is caused by considerable solid temperature difference. Melt fractions in the lower bed are almost the same due to less temperature difference. The melt fraction profiles are analyzed as listed in Table $\mathbf{6}$.

As iron ore diameter increases, average melt fraction decreases due to lower solid temperature. Ratio of undermelted sinter increases, while ratio of over-melted sinter decreases, which lead to decreasing of qualified sinter proportion and sinter yield.

Figure 12 shows thickness of molten zone under different initial iron ore particle diameters. It can be observed that 


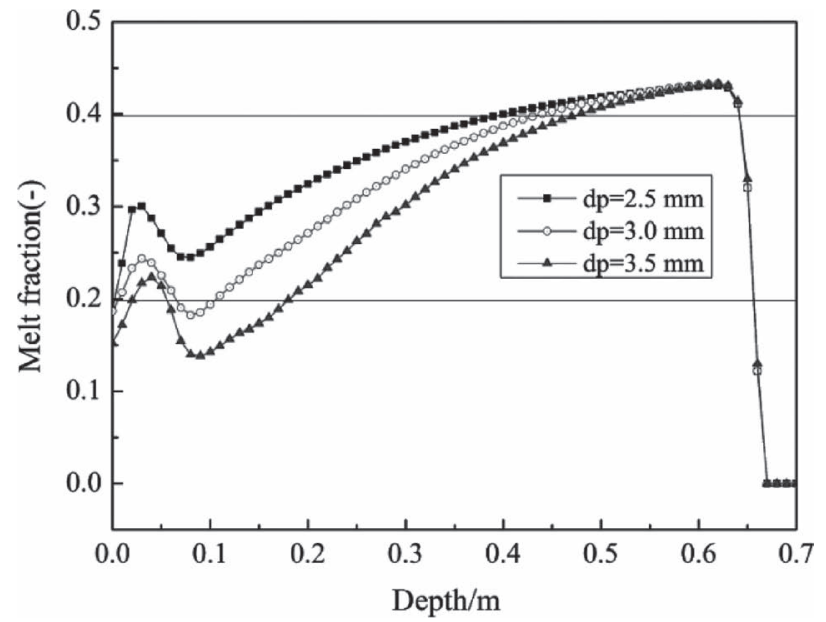

Fig. 11. Melt fractions vary with the height of the sinter pot.

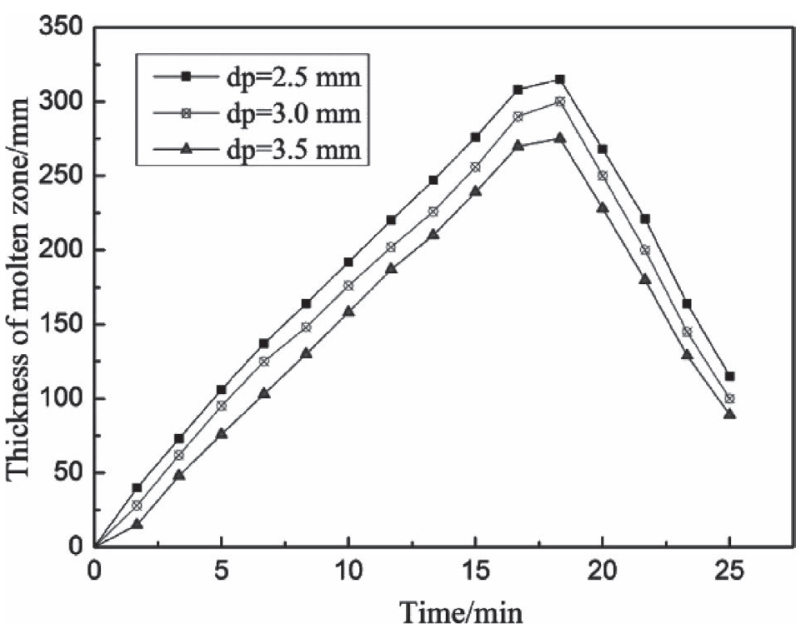

Fig. 12. Thickness of the molten zone changes with sintering time.

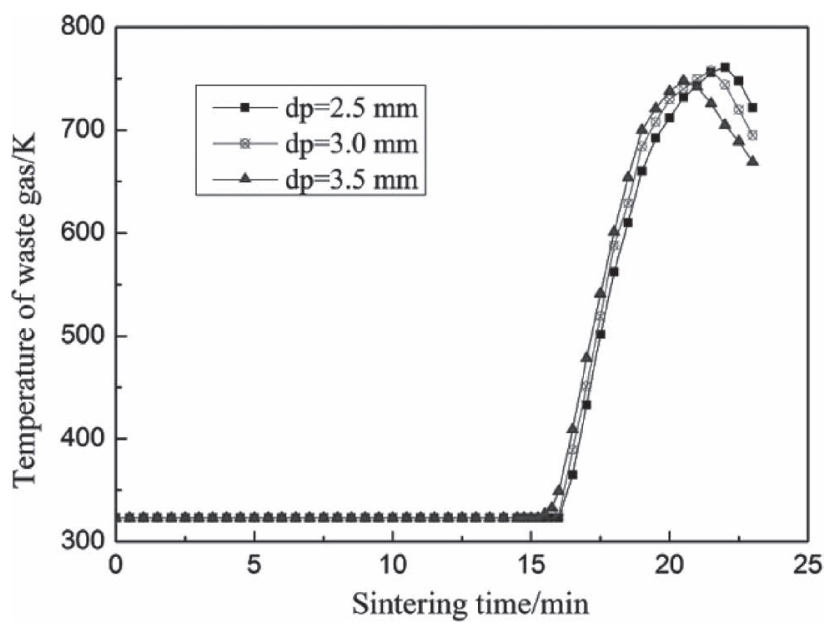

Fig. 13. Outlet gas temperatures vary with sintering time.

Table 6. Analysis of melt fractions under different iron ore particle diameters.

\begin{tabular}{ccccc}
\hline $\begin{array}{c}\text { Iron ore } \\
\text { diameter }\end{array}$ & $\begin{array}{c}\text { Average } \\
\text { melt fraction }\end{array}$ & $\begin{array}{c}\text { Under-melted } \\
\text { sinter }\end{array}$ & $\begin{array}{c}\text { Over-melted } \\
\text { sinter }\end{array}$ & Yield \\
\hline $2.5 \mathrm{~mm}$ & 0.352 & $7.8 \%$ & $26.3 \%$ & $65.9 \%$ \\
$3.0 \mathrm{~mm}$ & 0.338 & $12.6 \%$ & $23.9 \%$ & $63.5 \%$ \\
$3.5 \mathrm{~mm}$ & 0.313 & $20.4 \%$ & $18.3 \%$ & $61.3 \%$ \\
\hline
\end{tabular}

Table 7. Calculated sintering times and sinter diameters.

\begin{tabular}{ccc}
\hline Iron ore particle diameter & Sintering time & Sinter diameter \\
\hline $2.5 \mathrm{~mm}$ & $22.6 \mathrm{~min}$ & $26.7 \mathrm{~mm}$ \\
$3.0 \mathrm{~mm}$ & $21.4 \mathrm{~min}$ & $31.9 \mathrm{~mm}$ \\
$3.5 \mathrm{~mm}$ & $20.3 \mathrm{~min}$ & $37.1 \mathrm{~mm}$ \\
\hline
\end{tabular}

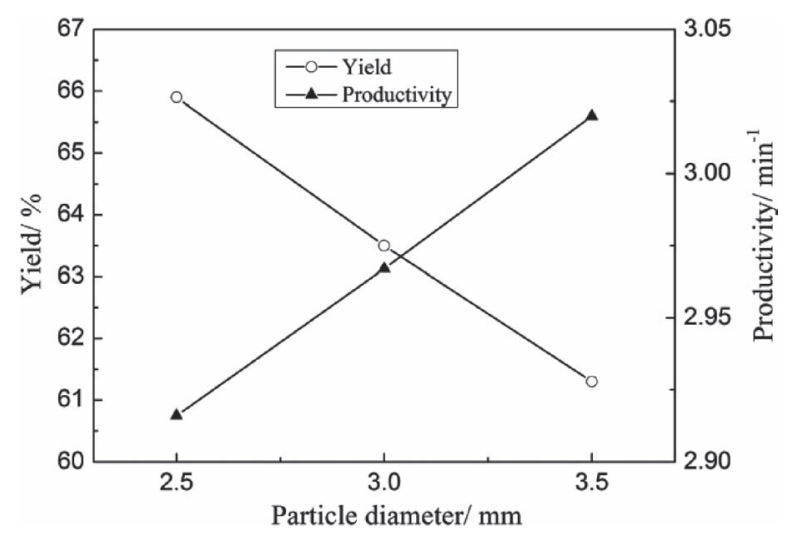

Fig. 14. Yield and productivity under different iron ore size.

coarser iron ore particle has thinner molten zone, which will results in improved permeability of the sinter bed.

Figure 13 shows waste gas temperature profiles for initial iron ore particle diameters. Calculated sintering times and sinter size are listed in Table 7.

As can be seen, sintering time was shortened with increasing of iron ore size due to improved permeability. Calculated sinter size increased about ten times. Sinter yield decreased from $65.9 \%$ to $61.3 \%$, and sintering time decreased from $22.6 \mathrm{~min}$ to $20.3 \mathrm{~min}$. Productivity equals yield divides time. Based on calculation, calculated productivities of sintering are shown in Fig. 14. For the reason that sintering time was shortened with increasing of iron ore size, productivity was improved although sinter yield decreased.

\section{Conclusion}

(1) A mathematical model of the iron ore sintering process was developed which described granule growth based on two dimensional homogeneous sphere packing theory. Most significant thermal phenomena and chemical reactions were considered. Employed with FLUENT software and a custom code, governing equations were solved in a sinter pot configuration. A sinter pot test was carried out and the calculated profiles agreed well with the measured.

(2) Profiles of temperature and melt fraction, contour of molten zone can be obtained based on simulation. Calculated granules diameter increased nearly ten times which was in line with the experimental data, while sintering time could be estimated. Besides, melt fraction was used as a criterion to predict sinter yield.

(3) Simulations were performed under different iron ore particle size in order to investigate its effect on sintering. Results showed that larger agglomeration was formed and molten zone became thinner when increasing iron ore particle diameters, which results in better permeability and 
shorter sintering time. Due to decreasing of solid temperature, extent of melting decreased. Ratio of under-melted sinter increased and over-melted sinter decreased, which lead to decreasing of sinter yield. Meanwhile, shorter sintering time leads to higher productivity although sinter yield decreased.

\section{Acknowledgments}

The authors thank the Hunan Provincial Innovation Foundation of China (No. CX2013B065). The authors also thank the anonymous referees for comments on this manuscript.

\section{Nomenclature}

$c_{\mathrm{CO} 2}$ : Concentration of $\mathrm{CO}_{2}$ in gases $\left(\mathrm{mol} / \mathrm{m}^{3}\right)$

$\mathrm{C}_{\mathrm{CO} 2}{ }^{*}$ : Equilibrium concentration of $\mathrm{CO}_{2}\left(\mathrm{~mol} / \mathrm{m}^{3}\right)$

$c_{\mathrm{O} 2}$ : Concentration of $\mathrm{O}_{2}\left(\mathrm{~mol} / \mathrm{m}^{3}\right)$

$c_{p, g}$ : Specific heat of gas $\left(\mathrm{kJ} /\left(\mathrm{m}^{3} \mathrm{~K}\right)\right)$

$c_{s}$ : Specific heat of solid $\left(\mathrm{kJ} /\left(\mathrm{m}^{3} \mathrm{~K}\right)\right)$

$d_{C}$ : Diameter of coke fine $(\mathrm{m})$

$d_{C 0}$ : Initial diameter of coke fine $(\mathrm{m})$

$d_{l}$ : Diameter of limestone particle $(\mathrm{m})$

$d_{l 0}$ : Initial diameter of limestone particle (m)

$d_{p}$ : Diameter of sinter granules $(\mathrm{m})$

$D$ : Equivalent diameter of a new sinter agglomeration (mm)

$D_{\mathrm{CO} 2}$ : Diffusion coefficient of $\mathrm{CO}_{2}\left(\mathrm{~m}^{2} / \mathrm{s}\right)$

$f_{m}$ : Volume fraction of melt $(-)$

$h$ : Convective coefficient $\left(\mathrm{J} /\left(\mathrm{m}^{2} \mathrm{~K} \mathrm{~s}\right)\right)$

$h_{v}$ : Volumetric convective heat transfer coefficient $(\mathrm{J} /$ $\left.\left(\mathrm{m}^{3} \mathrm{~K} \mathrm{~s}\right)\right)$

$\Delta H_{i}:$ Reaction heat $(\mathrm{J} / \mathrm{kg})$

$k_{f}$ : Film coefficient of mass transfer $(\mathrm{m} / \mathrm{s})$

$k_{c}$ : Reaction rate of coke combustion $(\mathrm{mol} / \mathrm{s})$

$L$ : Depth of the bed (m)

$M_{c}$ : Molecular weight of coke $(\mathrm{kg} / \mathrm{mol})$

$M_{H 2 O}$ : Molecular weight of water $(\mathrm{kg} / \mathrm{mol})$

$M_{l}$ : Molecular weight of limestone $(\mathrm{kg} / \mathrm{mol})$

$n_{C}$ : Number of coke fine

$n_{l}$ : Number of limestone particle

$P$ : Pressure $(\mathrm{Pa})$

$p_{H 2 O}$ : Vapor pressure $(\mathrm{Pa})$

$P_{v s a t}:$ Saturated vapor pressure $(\mathrm{Pa})$

$q_{m}$ : melting or solidifying heat $(\mathrm{J} / \mathrm{s})$

$r$ : Radius of finer particles $(\mathrm{mm})$

$R$ : Radius of the nuclei particle $(\mathrm{mm})$

$R_{i}$ : Reaction rate $\left(\mathrm{kg} /\left(\mathrm{m}^{3} \mathrm{~s}\right)\right)$

$R_{C}$ : Total rate constant for reaction of coke combustion $\left(\mathrm{mol} /\left(\mathrm{m}^{3} \mathrm{~s}\right)\right)$

$R_{l}$ : Total rate constant for reaction of limestone decomposition $\left(\mathrm{mol} /\left(\mathrm{m}^{3} \mathrm{~s}\right)\right)$

$R_{H-M}$ : Reaction rate of hematite reduction $\left(\mathrm{kg} /\left(\mathrm{m}^{3} \mathrm{~s}\right)\right)$

$R_{M-H}$ : Reaction rate of magnetite oxidation $\left(\mathrm{kg} /\left(\mathrm{m}^{3} \mathrm{~s}\right)\right)$

$R_{C O}$ : Reaction rate of CO combustion $\left(\mathrm{kg} /\left(\mathrm{m}^{3} \mathrm{~s}\right)\right)$

$R_{\mathrm{CO}-\mathrm{H} 2 \mathrm{O}}$ : Reaction rate of $\mathrm{CO}$ and $\mathrm{H}_{2} \mathrm{O}\left(\mathrm{kg} /\left(\mathrm{m}^{3} \mathrm{~s}\right)\right)$

$r_{\mathrm{H} 2 \mathrm{O}}$ : Drying rate $\left(\mathrm{mol} /\left(\mathrm{m}^{3} \mathrm{~s}\right)\right)$

$r_{c}$ : Reaction rate of a single coke particle $(\mathrm{mol} / \mathrm{s})$

$r_{\mathrm{H} 2 \mathrm{O}}$ : Drying rate $\left(\mathrm{mol} /\left(\mathrm{m}^{3} \mathrm{~s}\right)\right)$

$r_{l}$ : Reaction rate of a single limestone particle $(\mathrm{mol} / \mathrm{s})$

$r_{R}$ : Drying rate calculated from the partial pressure difference $\left(\mathrm{mol} /\left(\mathrm{m}^{3} \mathrm{~s}\right)\right)$
$T_{g}$ : Temperature of gas phase $(\mathrm{K})$

$T_{s}$ : Temperature of solid phase $(\mathrm{K})$

$T_{m}$ : Melting temperature $(\mathrm{K})$

$T_{\max }$ : Maximum solid temperature $(\mathrm{K})$

$v$ : Superficial velocity of gas $(\mathrm{m} / \mathrm{s})$

$W$ : Moisture content in the solid phase $(\mathrm{kg} / \mathrm{kg})$

$W_{C R}$ : Critical moisture content of solids $(\mathrm{kg} / \mathrm{kg})$

$Y_{i}$ : Mass fraction of gas phase species (-)

Greek symbols

$\varepsilon:$ Porosity (-)

$\lambda_{g}$ : Thermal conductivity of gas $(\mathrm{J} /(\mathrm{m} \mathrm{K} \mathrm{s}))$

$\lambda_{s}$ : thermal conductivity of solid $(\mathrm{J} /(\mathrm{m} \mathrm{K} \mathrm{s}))$

$\lambda_{s, e}:$ Effective thermal conductivity of solid $(\mathrm{J} /(\mathrm{m} \mathrm{K} \mathrm{s}))$

$\rho_{g}$ : Density of gas $\left(\mathrm{kg} / \mathrm{m}^{3}\right)$

$\rho_{b}$ : Density of bed $\left(\mathrm{kg} / \mathrm{m}^{3}\right)$

$\rho_{c}$ : Density of coke fine $\left(\mathrm{kg} / \mathrm{m}^{3}\right)$

$\rho_{l}$ : Density of limestone particle $\left(\mathrm{kg} / \mathrm{m}^{3}\right)$

$\sigma$ : Boltzmann constant $\left(\mathrm{W} /\left(\mathrm{m}^{2} \mathrm{~K}^{4}\right)\right)$

$\tau$ : Time (s)

$\mu_{g}:$ Viscosity of gas $(\mathrm{kg} /(\mathrm{m} \mathrm{s}))$

$\omega$ : Emissivity of solid (-)

\section{REFERENCES}

1) M. Naito, K. Takeda and Y. Matsui: ISIJ Int., 55 (2015), 7.

2) I. Muchi and J. Higuchi: Trans. Iron Steel Inst. Jpn., 12 (1972), 54.

3) R. W. Young: Ironmaking Steelmaking, 4 (1977), 321.

4) W. Yang, C. Ryu, S. Choi, E. Choi, D. Lee and W. Huh: ISIJ Int., 44 (2004), 492.

5) S. V. Komarov, H. Shibata, N. Hayashi and E. Kasai: J. Iron Steel Res. Int., 17 (2010), 1.

6) J. A. Castro, J. L. Pereira, V. S. Guiherme, E. P. Rocha and A. B. Franca: J. Mater. Res. Technol., 2 (2013), 323.

7) H. Zhou, J. P. Zhao, C. E. Loo, B. G. Ellis and K. F. Cen: ISIJ Int., 52 (2012), 2168.

8) H. J. Kang, S. M. Choi, W. Yang and B. Cho: ISIJ Int., 51 (2011), 1065 .

9) Y. Iwami, T. Yamamoto, T. Higuchi, K. Nushiro, M. Sato and N. Oyama: ISIJ Int., 53 (2013), 1633.

10) B. Zhang, J. M. Zhou and M. Li: J. Chem. Ind. Eng., 68 (2017), 1811 (in Chinese).

11) T. Umekage and S. Yuu: ISIJ Int., 49 (2009), 693.

12) V. Strezov, T. J. Evans, V. Zymla and L. Strezov: Int. J. Miner. Process., 100 (2011), 27.

13) F. Patisson, J. P. Bellot, D. Ablitzer, E. Marliere, C. Dulcy and J. M. Steiler: Ironmaking Steelmaking, 18 (1991), 89.

14) M. Pahlevaninezhad, M. D. Emami and M. Panjepour: Energy, 73 (2014), 160 .

15) B. Liu, Y. H. Feng, Z. Y. Jiang and X. X. Zhang: J. Chem. Ind. Eng., 63 (2012), 1344 (in Chinese).

16) A. Cores, A. Baboch, M. Muniz, S. Ferreira and J. Mochon: ISIJ Int., 50 (2010), 1089.

17) R. Bergstrand, J. Khosa, A. Waters and J. Garden: ISIJ Int., 45 (2005), 492.

18) R. Girimonte, V. Vivacqua and B. Formisani: Powder Technol., 297 (2016), 275

19) M. Li, Y. T. Mu, J. Y. Zhang and D. J. Xie: J. Cent. South Univ. Technol., 44 (2013), 1228 (in Chinese).

20) D. Kunii and M. Suzuki: Int. J. Heat Mass Transf., 10 (1967), 845

21) H. Thunman and B. Leckner: Fuel, 80 (2001), 473.

22) F. Patisson, J. P. Bellot and D. Ablitzer: Metall. Trans., 21B (1990), 37.

23) M. V. Ramos, E. Kasai, J. Kano and T. Nakamura: ISIJ Int., 40 (2000), 448.

24) N. K. Nath and K. Mitra: Ironmaking Steelmaking, 31 (2004), 199.

25) C. M. Yu: Numerical Analysis of Heat and Mass Transfer for Porous Materials, Tsinghua University Press, Beijing, (2011), 16 (in Chinese).

26) J. A. Castro, Y. Sazaki and J. Yagi: Mater. Res., 15 (2012), 848.

27) C. E. Loo, N. Tame and G. C. Penny: ISIJ Int., 52 (2012), 967.

28) J. Y. Fu, T. Jiang and D. Q. Zhu: Principle of Sintering and Pelletizing, Central South University of Technology Press, Changsha, (1996), 338 (in Chinese). 